\title{
STUDY OF ADVANCED MANUFACTURING TECHNOLOGIES FOR ACTIVE PARTS OF INJECTION MOLDS
}

\author{
Noémi Rita SOÓs ${ }^{1}$, Ödön János SOÓs ${ }^{2}$ \\ Technical University of Cluj-Napoca, Romania \\ ${ }^{1}$ noemi_soos@yahoo.com \\ ${ }^{2}$ soosodon@yahoo.com
}

\begin{abstract}
The main objective of this paper is to show the advantages of advanced manufacturing, such as high speed machining (HSM), for the active plates of injection molds. The goal of the experiment is to push the machine and the tools to the limit without reducing the surface quality of the manufactured part. The parts that are machined in this experiment are the active components of bucket injection mold. The mold core and nest is composed of several plates that have to form a whole when mounted together.
\end{abstract}

Keywords: CNC, Injection mold, HSM.

\section{Introduction}

Advanced manufacturing technologies are increasingly used due to CAM software. With the use of these tools manufacturers can achieve incredible results in the machining process. Tool life can be extended and manufacturing time reduced considerably. One such advanced technology is High Speed Machining (HSM). High speed machining is an advanced manufacturing technology with a huge impact on the manufacturing industry. High speed machining doesn't have a standardized definition in the technical literature. One definition is that the process ,involves machining at considerably higher cutting speeds and feeds than those used in conventional machining" [1]. The process of high speed machining can be used in a wide range of applications such as mold manufacturing, the aerospace industry and so on. The significance of high speed machining in production has in- creased with the evolution of new machines and tool development. This evolution of tools and machines give us the possibility of using this technology to reduce process time and to improve the surface quality of the parts. Surface quality and dimensional control is one of the most specified customer requirements and the major indicator of surface quality is the surface roughness.

\section{Experimental setup and data}

The machine used for the experiment is a Haas VF-3 CNC vertical machining centre with an axis travel of $1016 \mathrm{~mm}$ on the „X” axis $508 \mathrm{~mm}$ on the „Y” axis and $635 \mathrm{~mm}$ on the „Z” axis. The machining centre is equipped with $22.4 \mathrm{~kW}$ main spindles with inline drive and a coolant system of $3 / 4 \mathrm{HP}$. Additionally it has a wireless intuitive probing system (with which we can measure dimensions and set up parts for manufacturing) and an integrated software option of high speed machining that allows the ma- 
chine to read $G$ code in advance and optimize the acceleration and deceleration on the arc segments to obtain better surface quality.

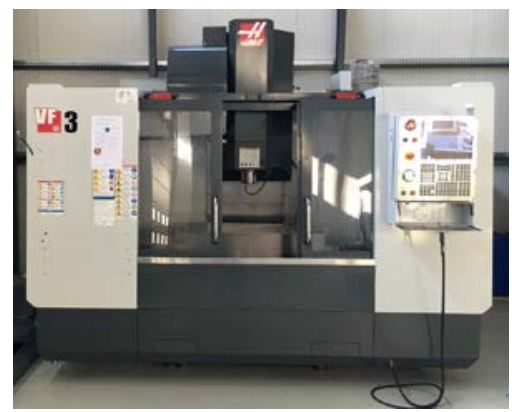

Figure 1. HAAS VF-3 Machine

Tools used for this experiment are from Ceratizit and Widea, dedicated for hard material removal and smooth finishing cuts on 3D surfaces. In the manufacturing process we will use a $10 \mathrm{~mm}$ end mill for roughing out the part with irregular helix, irregular pitch of the helix for increased material removal rate, and a $10 \mathrm{~mm}$ ball end mill for the surface finish for the 3D geometry of the mold. The irregular pitch ensures a smooth cutting action even with substantial depth of cut, allowing low cutting noise and low vibration. For the end mills, due to the gradually increasing helix angle, the core diameter is adapted to optimise chip evacuation.

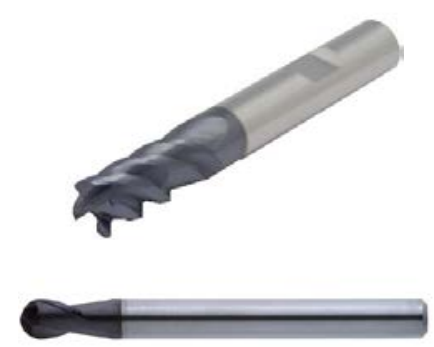

Figure 2. Milling tools used in the experiment [2]

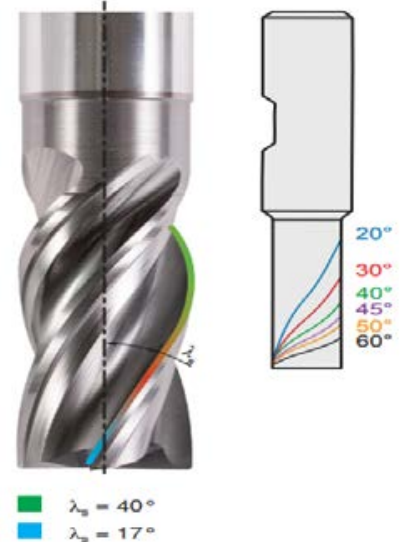

Figure 3. Milling tool with irregular pitch and angle used in the machining process [2]

- starting parameters for the $10 \mathrm{~mm}$ shoulder mill:

$\mathrm{v}_{\mathrm{c}}=100 \sim 130 \quad[\mathrm{~m} / \mathrm{min}]$ and $\mathrm{f}_{\mathrm{z}}=0.05$

[mm/tooth]

$\mathrm{a}_{\mathrm{e} \max }=1 * \mathrm{~d}[\mathrm{~mm}]$

$\mathrm{a}_{\mathrm{p} \max }=2 * \mathrm{~d}[\mathrm{~mm}]$

$$
\mathrm{n}=\left(\mathrm{v}_{\mathrm{c}} * 1000\right) /(\mathrm{d} * \pi)[\mathrm{rot} / \mathrm{min}]
$$

$\mathrm{f}=\mathrm{n}^{*} \mathrm{f}_{\mathrm{z}} * \mathrm{z}[\mathrm{mm} / \mathrm{min}]$

$\mathrm{n}_{\min }=100000 / 10 * \pi=3184 \mathrm{rot} / \mathrm{min}$

$\mathrm{n}_{\max }=130000 / 10 * \pi=4140 \mathrm{rot} / \mathrm{min}$

$\mathrm{f}_{\min }=3184 * 0.07 * 4=636 \mathrm{~mm} / \mathrm{min}$

$\mathrm{f}_{\max }=4140 * 0.05 * 4=828 \mathrm{~mm} / \mathrm{min}$

$\mathrm{a}_{\mathrm{e}}=10 \mathrm{~mm}$

$\mathrm{a}_{\mathrm{p}}=10 \mathrm{~mm}$

- starting parameters for the $10 \mathrm{~mm}$ ball end mill:

$\mathrm{v}_{\mathrm{c}}=115 \sim 135 \quad[\mathrm{~m} / \mathrm{min}]$ and $\mathrm{f}_{\mathrm{z}}=0.03$ [mm/tooth]

$\mathrm{a}_{\mathrm{e} \max }=1 * \mathrm{~d}[\mathrm{~mm}]$

$\mathrm{a}_{\mathrm{p} \max }=0.5 * \mathrm{~d}[\mathrm{~mm}]$

$\mathrm{n}_{\min }=115000 / 10 * \pi=3660 \mathrm{rot} / \mathrm{min}$

$\mathrm{n}_{\max }=180000 / 10 * \pi=4297 \mathrm{rot} / \mathrm{min}$

$\mathrm{f}_{\min }=3660 * 0.03 * 2=219.6 \mathrm{~mm} / \mathrm{min}$

$\mathrm{f}_{\max }=5729 * 0.03 * 2=343.7 \mathrm{~mm} / \mathrm{min}$

$\mathrm{a}_{\mathrm{e}}=10 \mathrm{~mm}$

$\mathrm{a}_{\mathrm{p}}=5 \mathrm{~mm}$ 


\subsection{The material of the active plates of the bucket mold and its struc- ture}

The material used for the active plates of the mold is 1.2311/ 40CrMnMo7 steel. This is a common alloy tool steel which is usually quenched and tempered. The 1.2311 steel has an excellent polishable property and is widely used for plastic injection molds. It has an excellent wear resistance that allows a high production of plastic parts in the injection molding process. This material can be case hardened (55 59 HRc) or nitrided (650 $\mathrm{HV}$ equivalent to 58HRc) if necessary.

Table 1. Chemical structure of the manufactured material [3]

\begin{tabular}{|c|c|c|c|}
\hline Carbon & $\begin{array}{c}0.35- \\
0.45 \%\end{array}$ & $\begin{array}{l}\text { Chromi- } \\
\text { um }\end{array}$ & $\begin{array}{c}1.80- \\
2.10 \%\end{array}$ \\
\hline $\begin{array}{l}\text { Manga- } \\
\text { nese }\end{array}$ & $\begin{array}{c}1.30- \\
1.60 \%\end{array}$ & $\begin{array}{l}\text { Molyb- } \\
\text { denum }\end{array}$ & $\begin{array}{c}0.15- \\
0.25 \%\end{array}$ \\
\hline Sulphur & $\begin{array}{c}0.03 \% \\
\max \end{array}$ & Silicon & $\begin{array}{c}0.20- \\
0.40 \%\end{array}$ \\
\hline $\begin{array}{l}\text { Phospho- } \\
\text { rous }\end{array}$ & $\begin{array}{c}0.03 \% \\
\max \end{array}$ & & \\
\hline
\end{tabular}

The chemical property of the material makes it relatively easy to machine but if the manufacturing strategy is not adequate then tool wear increases rapidly, which influences the surface quality of the part.

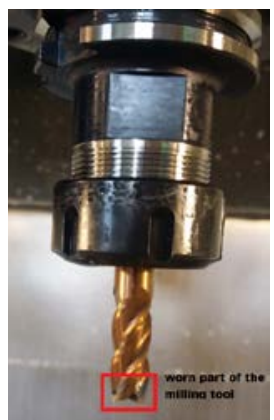

Figure 4. Worn part of the tool due to inadequate milling parameters and strategy
The structure of the active plates for the bucket mold is shown in the Figure 5.

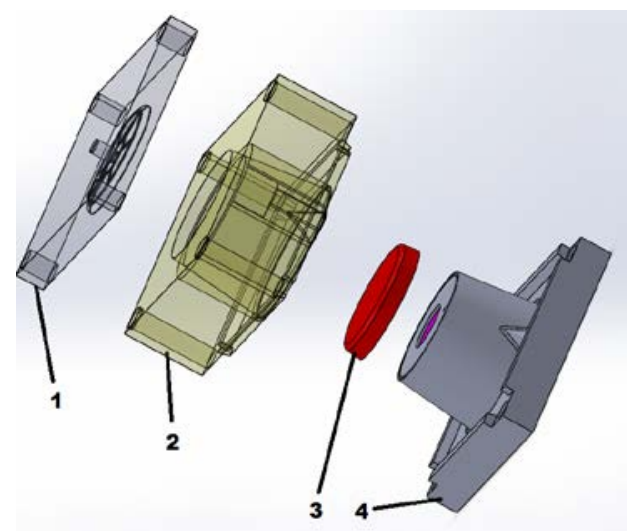

Figure 5. The active plates of the bucket mold

The bucket mold consists of 4 individual parts. Parts 1 and 2 from Figure 5 is the nest of the mold and forms the exterior of the bucket after the plastic injection. Parts 3 and 4 in the above image form the core of the mold that interlock with the internal surfaces of the injected product. The machining of parts 1, 2, 3 and 4 is performed separately due to the gabarit of the mold, and the finishing pass is achieved in mounted state (finishing pass for 1 and 2 mounted together and 3 and 4 mounted together) of the active plates.

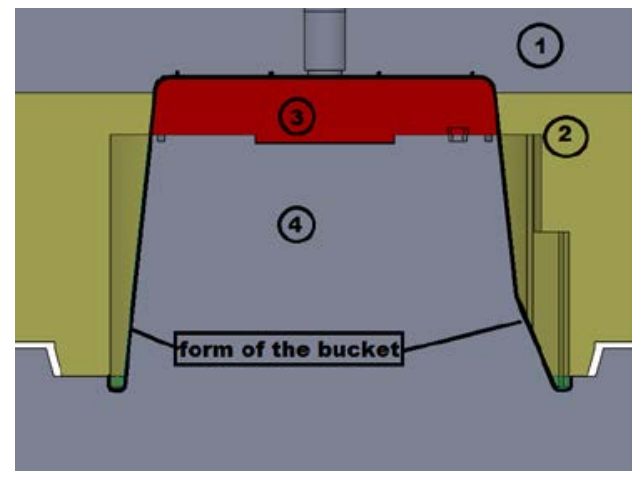

Figure 6. Active plates mounted together forming the bucket 
The design of the bucket mold makes it possible to evacuate the part easily due to the steep angles and the ejection system that of pneumatic and hydraulic drives. The pneumatic drive strips the bucket from the surface of the mold and the hydraulic piston ejects the part from the mold.

\section{Experimental results}

For the study of high speed machining technology we used a CAM software with the capacity for high speed strategies and an adequate G-code generating system. For this purpose we used Mastercam, a global leader CAM software that has integrated HSM strategies combined with dynamic milling. This allows us to use state of the art programing and exemplify the benefits of this strategy.

To begin we manufactured the active plate 3 (see Figure 5. and 6.) of the mold. Imputed parameters and strategy used:

- $\quad$ Strategy (HSM): surface high speed roughing toolpath;

- $\quad$ Starting spindle speed: 3200 RPM;

- $\quad$ Feed rate: 600 mm/ min;

- Stepdown $10 \mathrm{~mm}$, entry mode helical interpolation;

- $\quad$ Step-power 5 mm;

- $\quad$ Estimated cycle time 1h:10min
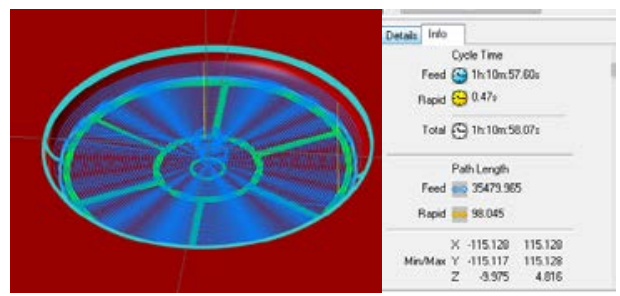

Figure 7. Toolpath of the HSM strategy and estimated milling time

After starting the manufacturing, due to the low spindle load we started increasing the feed rate of the milling tool to observe the impact on the manufactured part and milling tool. The final limit of the operation was a spindle speed of $3520 \mathrm{rpm}$ and a feed rate of $2040 \mathrm{~mm} /$ minute seen in Figure 8 . Even with a $340 \%$ increase of the feed rate and the $110 \%$ increase in spindle speed the load on the spindle was still low: approximately $16 \%$ in full cutting depth. This was possible due to the HSM toolpath that reduce spindle load and increased tool life. With this strategy we reduced the manufacturing time to 18 minutes instead of 70 minutes as estimated.

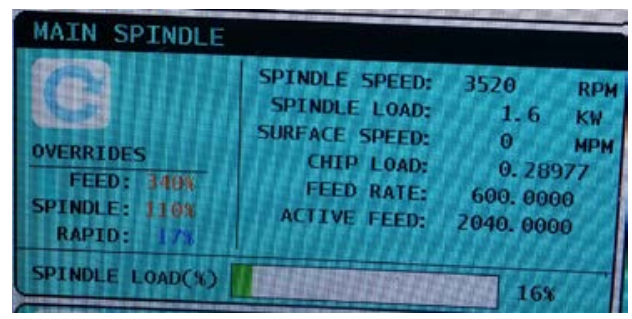

Figure 8. Override of the starting milling parameters

At the completion of the milling process we verified the shoulder mill and the surface quality of the part. The shoulder mill was like brand new and the surface of the part was excellent for a roughing strategy.

After roughing, we used a 2D high speed, and a high speed flowline strategy and obtained a very smooth surface finish.

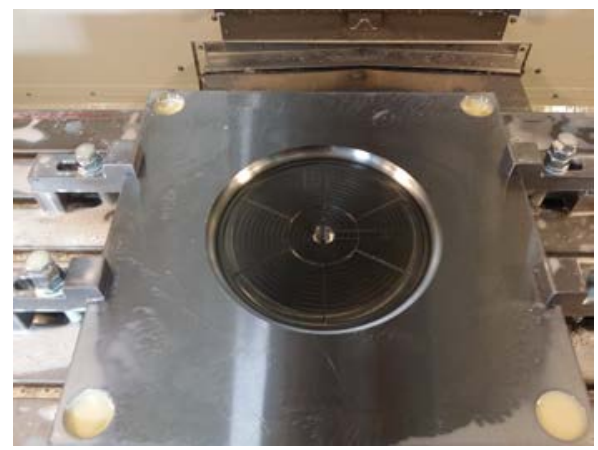

Figure 9. Finished active plate number 3

The quality of the machined surface was better than expected and in this case it was considered a finished part needing no sub- 
sequent polishing. The achieved surface roughness was between $0.4-0.8 \mu \mathrm{m}$.

For active plate number 4 we used the same finishing HSM strategy, surface finish flowline with a width of cut $0.5 \mathrm{~mm}$ and a depth of cut of $0.3 \mathrm{~mm}$ to obtain a smooth finish. The depth of cut was made in a spiral mode without any repositioning of the tool and a continuous cut of material. This offered a reduced cycle time and a good quality finish of the machined surface. In this case, too, the manufacturing cycle time was reduced up to $45 \%$ compared to the estimated theoretical time after pushing feeds and speeds to the limit. Due to low spindle load and a good chip evacuation the milling tool was in perfect condition after the finished operation.

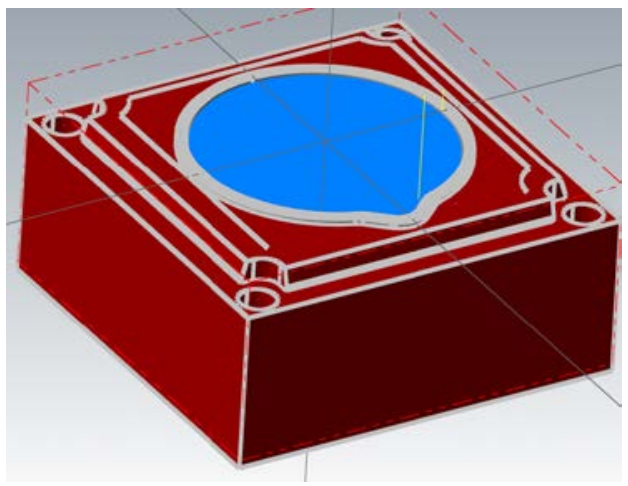

Figure 10. Surface flowline strategy from Mastercam

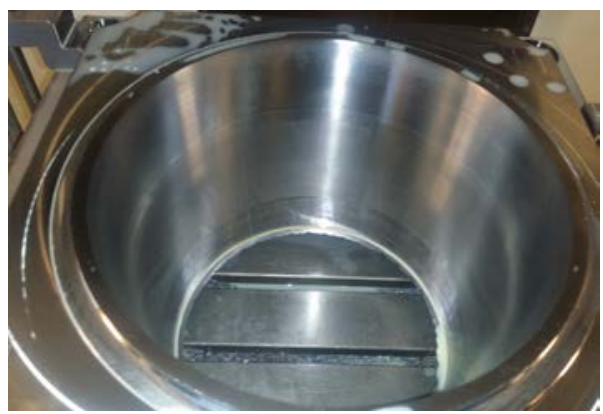

Figure 11. Finished active plate number 4
Because active plate number 4 had a depth of $245 \mathrm{~mm}$ in the machining process small vibrations appeared. Even with this vibration the surface quality was good - between 1 - $1.6 \mu \mathrm{m}$ - but it had to be under $0.8 \mu \mathrm{m}$ for the product to be adequate for the client. A polishing operation was added to the process with special abrasive paper and fine abrasive paste. After a short polishing by hand the required surface quality was within requested parameters.

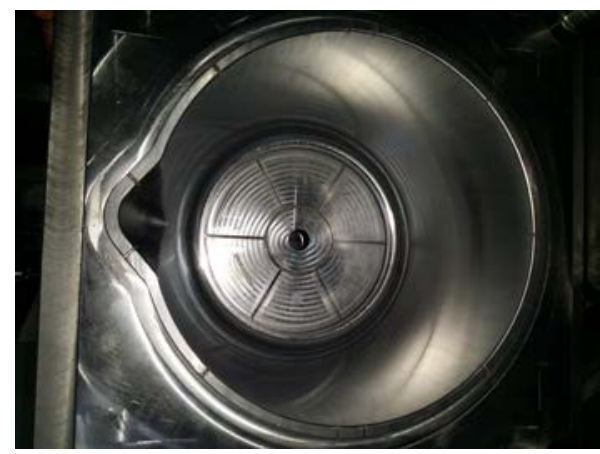

Figure 12. Assembled part $(3+4)$

The same high speed machining strategies were applied for active plates 1 and 2 of the bucket mold. The same results were observed in cycle time and tool load decrease, and in good surface quality. In Figure 13. the assembled product can be seen (active plate $1+2)$.

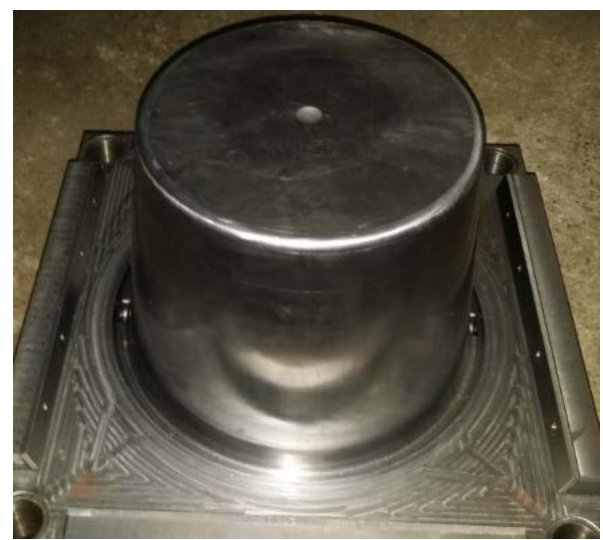

Figure 13. Assembled part $(1+2)$ 


\section{Conclusions}

The experimental results after the manufacturing of the active plates of the bucket mold from the material 1.2311 with HSM strategies are:

- Using HSM strategies and adequate tooling, the forces in the milling operation reduce significantly, allowing higher speed and feed rates for the process;

- The cycle time is reduced significantly with this type of strategy and has a positive impact on cost reduction;

- The surface quality is significantly improved compared to classic manufacturing technologies;

- Tool life increases and spindle load decreases with HSM and dynamical milling strategies.
In conclusion, we can affirm that using HSM technology we can reduce machining cycle time, manufacturing costs, increase surface quality and tool life. The most significant impact of HSM is the environmental benefit: less energy consumption, less broken and worn tools, and less pollution.

\section{References}

[1] Begic-Hajdarevic D., Cekic A., Kulenovic M.: Experimental Study on the High Speed Machining of Hardened Steel. Procedia Engineering 69, 2014, 291-295.

[2] Cutting solutions by Ceratizit: Cutting tools. 2016, 1041-1043; 1067-1068.

[3] West Yorkshire Steel, 1.2311 Tool Steel https://www.westyorkssteel.com/steelspecifications/werkstoff-standards/tool-steelw-nr/1-2311/ (accesed 1 Oct. 2017). 